\title{
Oceanography
}

CITATION

Alt, J. 2013. Review of Diversity of Hydrothermal Systems on Slow Spreading Ocean Ridges, edited by P.A. Rona, C.W. Devey, J. Dyment, and B.J. Murton. Oceanography 26(1):108-109, http://dx.doi.org/10.5670/oceanog.2013.15.

DOI

http://dx.doi.org/10.5670/oceanog.2013.15

COPYRIGHT

This article has been published in Oceanography, Volume 26, Number 1, a quarterly journal of The Oceanography Society. Copyright 2013 by The Oceanography Society. All rights reserved.

USAGE

Permission is granted to copy this article for use in teaching and research. Republication, systematic reproduction, or collective redistribution of any portion of this article by photocopy machine, reposting, or other means is permitted only with the approval of The Oceanography Society. Send all correspondence to: info@tos.org or The Oceanography Society, PO Box 1931, Rockville, MD 20849-1931, USA. 


\section{Diversity of Hydrothermal Systems on Slow Spreading Ocean Ridges}

Edited by P.A. Rona, C.W. Devey,

J. Dyment, and B.J. Murton, 2010,

American Geophysical Union, 440 pages,

ISBN: 978-0-87590-478-8, \$129 US

\section{REVIEWED BY JEFFREY ALT}

The global mid-ocean ridge system spreads over a spectrum of rates, and oceanic crust formed at slow and ultraslow spreading ridges $\left(<40 \mathrm{~mm} \mathrm{yr}^{-1}\right)$ differs from the more "ideal" layered structure formed at faster spreading ridges. Tectonic activity is more important at slower spreading ridges, resulting in local uplift and exposure of mantle peridotites that can be intruded by mafic melts and that are exposed in oceanic core complexes. Thus, hydrothermal activity at slow spreading ridges can range from mafic- to ultramafic-hosted systems that have different rock and fluid compositions; both of them can occur over a range of temperatures. Faulting can control the depth of hydrothermal circulation as well as the location of hydrothermal vents and deposits.

The book Diversity of Hydrothermal Systems On Slow Spreading Ocean Ridges, edited by Peter Rona, Colin Devey, Jérôme Dyment, and Bramley Murton, is the most recent of several books devoted to submarine hydrothermal activity in the American Geophysical Union Monograph series. Some of its chapters review different aspects of hydrothermal activity at slow spreading ridges and include details as well as good overviews. Others give regional summaries or present recent advances in understanding more specific aspects of these hydrothermal systems and their effects. The chapters do not seem to be arranged in any systematic order, other than the Introduction and the short chapter by Rona, which gives a historical perspective of exploration for hydrothermal activity and documents discoveries on the MidAtlantic Ridge. As a specialist, I found the volume to be an excellent up-to-date summary, and it should also be accessible for those in other fields interested in getting an overview of hydrothermal systems at slow spreading ridges.

The chapter by Deborah Kelley and Timothy Shank provides a nice review of hydrothermal activity in slow spreading environments. It includes a useful three-tier classification of hydrothermal systems. Those in Type I are the more typical high-temperature hydrothermal systems hosted in mafic rocks, with acid hydrothermal fluids that vent at black smokers. Type II hydrothermal systems are ultramafic-hosted and driven by gabbroic intrusions, with black smokers venting hydrothermal fluids that contain carbon dioxide from mafic magmas as well as methane and hydrocarbons derived from serpentinization reactions. Type III systems are hosted in ultramafic rocks, and the low-temperature hydrothermal fluids are driven by cooling of mantle material. This chapter also reviews biological activity related to hydrothermal vents at slow spreading ridges and offers a detailed table that lists all species found at nine sites.

Henrietta Edmonds summarizes and provides a table of hydrothermal fluid compositions for 13 sites, which include low- and high-temperature systems in mafic- and ultramafic-hosted settings. Compared to fluids in high-temperature

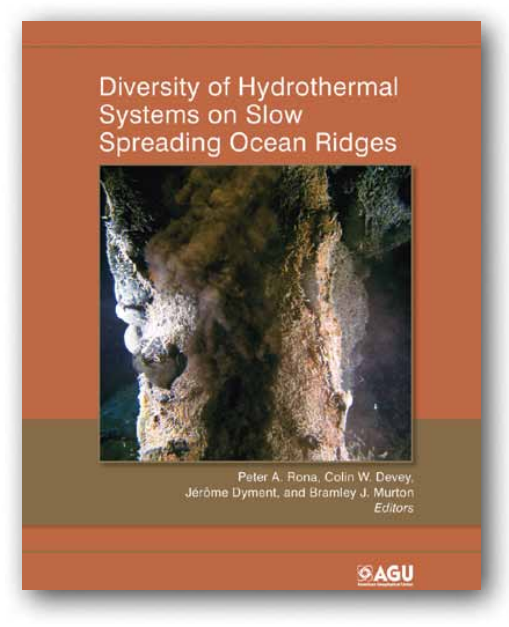

mafic systems, those in ultramafic rocks show the effects of serpentinization reactions, are enriched in methane and hydrogen, and have low silica concentrations. The chapter by William Seyfried et al. uses theoretical modeling combined with results from experiments to provide a new analysis of the controls on hydrothermal fluid compositions in high-temperature ultramafic-hosted hydrothermal systems. The authors suggest that reaction of plagioclase + olivine assemblages can result in relatively low $\mathrm{pH}$, moderately elevated silica, and high hydrogen concentrations compared to reaction of ultramafic rocks only.

Yves Fouquet et al. review hydrothermal deposits, providing details of their tectonic settings, host lithologies, fluid compositions, and mineralogy. These authors show that sulfide deposits associated with ultramafic rocks are enriched in $\mathrm{Cu}, \mathrm{Zn}, \mathrm{Co}, \mathrm{Au}$, and $\mathrm{Ni}$ compared to those in mafic systems, and they provide an integrated schematic model for how these deposits form. Robert Lowell's chapter discusses constraints on hydrothermal circulation from heat budgets and divides hydrothermal systems into high-temperature, high-heat output systems (e.g., TAG and Rainbow hydrothermal systems on the Mid-Atlantic Ridge) and low-temperature off-axis 
systems (e.g., Lost City on the MidAtlantic Ridge). He also distinguishes low-heat output systems such as Broken Spur (also on the Mid-Atlantic Ridge), which is in its waning stages.

Maurice Tivey and Jérôme Dyment review the magnetic signatures evident in basement beneath hydrothermal vent sites on slow spreading ridges. They show that magnetic signatures are local scale effects of the size of individual vent fields that are best studied with nearbottom high-resolution surveys.

Three chapters focus on tectonics to varying extents. The term "oceanic core complex" is derived from core complexes on land, and Barbara John and Michael Cheadle compare detachment faults in mid-ocean ridge and continental settings, including structure, thermal conditions, and hydrothermal alteration. In their chapter, Andrew McCaig et al. address links among faulting, hydrothermal flow, and reaction with basement rocks. They use modeling and strontium and oxygen isotope data as well as constraints from geophysical measurements at the TAG hydrothermal field to provide a detailed description of fluid flow and hydrothermal alteration of basement core complexes in relation to detachment faulting. The chapter by Wayne Crawford et al. integrates various geophysical data to document the magma chamber beneath the Lucky Strike hydrothermal site on the Mid-Atlantic Ridge as well as faults and crustal structure. They then make inferences about tectonic and magmatic controls on crustal structure and hydrothermal circulation.

Two chapters deal mainly with serpentinization, with a particular focus on production of hydrogen and methane. Jean Luc Charlou et al. summarize fluid compositions for high- and low-temperature ultramafic-hosted hydrothermal systems. They show that, despite the effects of supercritical phase separation, the high hydrogen concentrations resulting from serpentinization are globally significant. They also discuss synthesis of light hydrocarbons by Fischer-Tropsch type reactions in these hydrothermal systems. Mathilde Cannat et al. make a robust quantitative estimate of the abundance of serpentinite in oceanic basement and use it to calculate fluxes of methane and hydrogen from serpentinization. They employ seafloor morphology, gravity, and crustal thickness data, along with seafloor sampling, to estimate that $9-32 \%$ of oceanic crust formed at slow spreading rates consists of peridotite. Cannat et al. estimate a global flux of hydrogen from serpentinization of $16.7 \times 10^{10} \mathrm{~mol} \mathrm{yr}^{-1}$, the same order of magnitude as that estimated in the Charlou et al. chapter $\left(8.9 \times 10^{10} \mathrm{~mol} \mathrm{yr}^{-1}\right)$.

Three chapters provide regional summaries of hydrothermal activity. Although the Arctic Mid-Ocean Ridges are particularly difficult to explore, the chapter by Rolf Pedersen et al. describes abundant hydrothermal activity and the geologic/tectonic settings on these slow and ultraslow spreading ridges between Iceland and $\sim 90^{\circ} \mathrm{N}$. The authors' evidence includes high- and low-temperature vents and deposits related to volcanic activity and to rifting of volcanic as well as ultramafic basement. In another chapter, Devey et al. document ridge morphology and settings of known hydrothermal deposits on the southern Mid-Atlantic Ridge, and they use these characteristics to predict other likely areas of hydrothermal activity in the southern Atlantic. The chapter by Daniel Sauter and Mathilde Cannat focuses on the volcanic/tectonic construction of volcanic and avolcanic sections of the ultraslow spreading Southwest Indian Ridge, but the chapter has implications for various types of hydrothermal activity.

Drilling from land into hydrothermal systems on Iceland, which sits atop the Mid-Atlantic Ridge, provides a unique view into the subsurface of active hydrothermal systems. The chapter by Wilfred Elders and Guðmundur Ómar Fridleifsson discusses results from the Iceland Deep Drilling Project that penetrated $2.1 \mathrm{~km}$ into basement. The goal of the project is to penetrate the supercritical region of Iceland's hydrothermal systems in order to better understand the magmatic-hydrothermal processes of other mid-ocean ridge systems.

The chapter by Nicole Le Bris and Sébastien Duperron is the only one to deal solely with biology. They use the mussel Bathymodiolus, which contains both sulfide- and methane-oxidizing symbionts, to document chemosynthetic processes and biogeochemical energy pathways that occur at hydrothermal vents. They suggest that these mussels contain the two symbionts in order to adapt to both $\mathrm{H}_{2} \mathrm{~S}$-rich (mafic-hosted) and methane-rich (ultramafic-hosted) hydrothermal vents.

The book thus delivers on its title, providing a good summary of the diversity of hydrothermal systems on slow spreading ridges from the perspectives of structure, hydrothermal fluids, hydrothermal deposits, heat-budgets, magnetics, and biology. The book should be a valuable reference for those interested in submarine hydrothermal activity.

\footnotetext{
Jeffrey Alt (jalt@umich.edu) is Research Professor, Department of Earth and Environmental Sciences, The University of Michigan, Ann Arbor, MI, USA.
} 